\title{
A Lagrangian oil spill transport model for the Red Sea
}

\section{R. Periáñez}

Dpt Física Aplicada I, ETSIA, Universidad de Sevilla, Ctra Utrera km 1, 41013 Sevilla, Spain

\section{A R T I C L E I N F O}

\section{Keywords:}

Red Sea

Tide

Baroclinic circulation

Oil spill

Transport

Oil evaporation

\begin{abstract}
A B S T R A C T
An oil spill model was developed for the Red Sea. It uses detailed data on water circulation: instantaneous tidal currents, tidal residuals (both from a tidal model specifically applied to the Red Sea) and baroclinic circulation derived from HYCOM ocean model. The model can also incorporate forecasts of local (in the spill area) winds. The transport model is Lagrangian and includes advection/diffusion plus specific processes for oil, as buoyancy, decomposition and evaporation. Results of the tidal model were compared with observations in the sea. The transport model was first applied to passive particles to compare the significance in advective processes of the components of the current (tidal, tidal residual, baroclinic currents) over several areas and seasons and then it was applied to some oil spills: the model output was compared with results from previous simulations and it was also applied to hypothetical oil spills.
\end{abstract}

\section{Introduction}

Lagrangian transport models are useful tools which have been extensively used in oil spill modelling in different marine areas Korotenko et al., 2004; Periáñez and Pascual-Granged, 2008; Proctor et al., 1994b,a; Jordi et al., 2006 among many others). Efforts were also made after the Deepwater Horizon oil spill in the Gulf of Mexico in 2010 (Mariano et al., 2011) and the Prestige accident in NW Spain in 2002 (Carracedo et al., 2006; Sotillo et al., 2008).

The Red Sea is located between the Indian Ocean and the Mediterranean Sea, connected to the last through the Canal of Suez. It is connected with the Gulf of Aden (Indian Ocean) through Bab elMandeb (BeM) Strait. Because of the dry climate there is an excess of evaporation over precipitation and there is not river runoff. Dense water flows out the Red Sea through BeM, and this subsurface outflow is compensated by a surface inflow from the Indian Ocean (Pickard and Emery, 1982). This exchange pattern is modulated by seasonal (monsoon) variations (Guo et al., 2018). The winter flow regime is apparent between October and May, and it is characterized by a twolayer inverse estuarine flow. This pattern is replaced in summer by a three-layer flow characterized by a shallow outflow of the Red Sea surface waters, an intrusion of relatively fresh and cold Gulf of Aden intermediate waters, and finally a deep hypersaline outflow of the Red Sea waters (Sofianos and Johns, 2007). Observations made by these authors reveal a very intense and complicated circulation pattern, with a permanent cyclonic gyre in the northern part and a number of them in the central and southern basins. Tides (Pugh, 1987) are closely represented by a standing wave with a single central node in the case of semidiurnal tides. Diurnal tides are similar, but the node is displaced to the south.
Due to its strategic location between the Mediterranean Sea and the Indian Ocean, the Red Sea suffers intense shipping activities, including of course the traffic of oil tankers. Thus, it is an area potentially exposed to oil spills due to accidental releases which could damage the environment. Therefore, it is useful to have knowledge on the transport processes which occur within the Red Sea as well as predictive tools which could support decision-making in case of an accidental oil spill.

However, few oil spill models for the Red Sea are described in literature. Nasr and Smith (2006) present a local spill model for the Gulf of Suez, but they do not provide details on how water circulation (the essential transport driving mechanism) is obtained: only that a water current map was constructed integrating data from different sources, including observations by sea captains. Ahmed et al. (2012a) describe a local model as well, applied to a hypothetical spill in Sudanese coast. Again, surface water currents are provided to the transport model in a "map form that identifies the spatial variation in the water velocities" (sic), but details are not given. The model was run for prevailing (steady) wind conditions of summer and winter. Ahmed et al. (2012b) present an Eulerian model for the same area, which is used to estimate a diffusion coefficient. Again, it is only mentioned that currents were obtained from field measurements.

In this paper, an oil spill transport model which covers the whole Red Sea is presented. The most significant differences with respect to previous works are:

1. Model domain: it covers the whole sea instead of being a local model.

E-mail address: rperianez@us.es. 
2. Water circulation: the model uses detailed data for water circulation. It includes five tidal constituents and their corresponding residuals derived from a high resolution tidal model, previously tested and validated in other regions. Tidal analysis is used to calculate the tidal current at any time and position in the Red Sea. In addition, baroclinic circulation (daily values) is obtained from the widely tested and applied HYCOM ocean model.

3. Winds: forecasts of local winds (in the spill area) may be included in the model to deal with changing wind conditions both in speed and direction, caused for instance by a local storm not described within HYCOM.

Of course, a model is just a description of very complex environmental processes. If the purpose of a given model consists of its use as a tool to support decision-making after an accidental oil spill in the sea, it has to be relatively simple to run (required input data should be as few as possible) and running times should be as short as possible while offering reasonable predictive skills. These conditions imply that approximations and simplifications are required; thus some processes have to be parameterized or neglected, retaining the most significant ones. The different simplifications used in the present model are described along the paper. Nevertheless, it goes further than considering the oil spill as a number of passive particles experiencing advection and diffusion as in Bourgault et al. (2014) and Díaz et al. (2008) for instance.

The model is described in Section 2, where the hydrodynamic and spill transport components are presented separately. Results are described in Section 3; results from the tidal model are initially presented and compared with observations, as well as some examples of HYCOM baroclinic circulation (Section 3.1). Results from the transport model are given in Section 3.2. First, the model was applied to passive particles to assess the significance of the components of the water currents (tidal current, tide residual current, baroclinic circulation) in transport processes in different regions of the Red Sea and different seasons. Then some examples of applications to oil spills are shown. The model output was first compared with results of some other earlier simulations and then to hypothetical oil spills to illustrate model capabilities.

\section{Methods}

\subsection{Tidal modelling}

A two dimensional depth-averaged model was used to simulate tides in the Red Sea. The model provides the sea surface elevations and water currents at each point in the model domain and for each time step. Elevations and currents are treated through standard tidal analysis (Pugh, 1987, Chapter 4) and tidal constants are then calculated and stored. Five constituents were considered: three semidiurnal $\left(M_{2}, S_{2}\right.$ and $N_{2}$ ) and two diurnal $\left(K_{1}\right.$ and $O_{1}$ ). Thus, the tidal model equations (see for instance Periáñez, 2012) are solved for each constituent and tidal analysis is also carried out for each constituent separately. A residual transport cannot be produced by the pure harmonic currents given by the tidal analysis, thus tidal residuals were calculated as well, in the form of Eulerian residual transport. The procedure may be seen in detail in Periáñez (2012). Hydrodynamic equations (which essentially express conservation of mass and momentum) are solved using explicit finite difference schemes, with a second order accuracy scheme for nonlinear terms. Boundary conditions consist of specifying water surface elevations, from measured tidal constants, along the open boundaries of the domain. Measurements are given, for instance, in Madah et al. (2015). The model has been successfully tested in the past for several regions at different spatial scales (Periáñez, 2007, 2009, 2012; Periáñez et al., 2013; Periáñez and Abril, 2014).

\subsection{Baroclinic circulation}

HYCOM (Hybrid Coordinate Ocean Model, Bleck, 2001) output was used to describe baroclinic circulation in the Red Sea. It is a primitive equation general circulation model with 40 vertical layers whose thickness increase from surface to the sea bed $(2 \mathrm{~m}$ near the surface to $1000 \mathrm{~m}$ in the deepest ocean). Horizontal resolution is $0.08^{\circ}$ both in latitude and longitude. A wide number of HYCOM model applications over all the world may be seen in the model web page (https://www.hycom.org/). Daily currents for the area of interest were downloaded from HYCOM data server.

\subsection{Particle-tracking oil-spill model}

A pollutant release into the sea is simulated in a particle-tracking (Lagrangian) model by means of a number of particles, each one equivalent to a number of units, whose trajectories are calculated along time during the simulated period. The spill model considers physical transport (advection due to water currents and mixing due to turbulence) plus some specific processes for oil, as buoyancy, evaporation and decomposition. The transport of the oil spill as a surface film and the effects of surface tension are not included in this model, although their theoretical description may be seen in Maderich et al. (2012).

Advection is computed solving the following equation for each particle:

$\Delta x=u \Delta t+\frac{\partial K_{h}}{\partial x} \Delta t$

$\Delta y=v \Delta t+\frac{\partial K_{h}}{\partial y} \Delta t$

where $\Delta x$ and $\Delta y$ are the changes in particle position $(x, y)$; and $u$ and $v$ are water velocity components in the west-east and south-north directions, respectively, at the particle position and depth; and for the moment when the calculation is done, since currents are changing in time. Derivatives of the horizontal diffusion coefficient $\left(K_{h}\right)$ above prevent the artificial accumulation of particles in regions of low diffusivity (Proehl et al., 2005; Lynch et al., 2015). Constant diffusion coefficients are used in the present work, thus these term are not relevant here. The use of constant diffusivities is just a simplification to speed up calculations, although of course more complex descriptions could be implemented, as the Smagorinsky scheme (Cushman-Roisin and Beckers, 2011). Actually, Lagrangian transport models were applied to the Pacific Ocean (Periáñez et al., 2019), some with constant and some with Smagorinsky diffusivities, providing comparable results.

It must be commented that a first order accuracy equation is used to describe advection. However, Elliott and Clarke (1998) did not find improvements in results when a second order accuracy scheme was used to simulate the movement of surface drifters, with respect to the first order equation. Moreover, in marine transport problems, the effects of turbulence will mask any small errors in the advection scheme.

Vertical currents in the sea are small; dimensional analysis (Dyke, 2001) shows that they are typically in the order of $10^{-5}$ to $10^{-4} \mathrm{~m} / \mathrm{s}$. Thus vertical advection is masked by vertical mixing due to turbulence. As a consequence, it is a common approach to neglect vertical advection in marine transport modelling. Water currents, $u(x, y, z, t)$ and $v(x, y, z, t)$, are the addition of tidal current, tidal residual, baroclinic current and local wind induced current. Of course, this is an approximation which neglects the non-linear interactions which may occur between baroclinic currents and tides, as well as non-linear interactions between the different tide constituents.

The baroclinic current for each day of the year is obtained from the downloaded HYCOM data, as mentioned above. Tidal sea surface elevation for the corresponding instant of time $t$ at a given location is obtained from the calculated tidal amplitudes and phases as:

$Z(t)=H_{0}+\sum_{i=1}^{5} h_{i} f_{i} \cos \left(w_{i} t-g_{i}+V_{i}\right)$ 
where $H_{0}$ is the location datum, $w_{i}$ is frequency of constituent $i$ (five are included as mentioned before), $h_{i}$ and $g_{i}$ are amplitude and phase (adapted phase, i.e., for the local time meridian) for the corresponding location (calculated from the tidal analysis), $f_{i}$ is nodal factor and $V_{i}$ the equilibrium argument of the constituent at Greenwich. Nodal factors and equilibrium arguments for year 2020 are used. Thus, the beginning of this year is $t=0$. Of course, values for any other year may be used. The same treatment is given to tidal currents, as usual in this type of models (Proctor et al., 1994b; Elliott et al., 2001; Periáñez and PascualGranged, 2008). A standard current profile is used to generate a vertical structure in tidal currents (depth averaged currents are provided by the tidal model), since these currents decrease from sea surface to the bottom due to friction with the seabed. Details may be seen in Pugh (1987) and Periáñez and Pascual-Granged (2008) and are not repeated here.

The wind-induced current decreases, below a depth $z_{1}$ (wind-driven surface layer thickness), logarithmically to zero at a depth $z_{2}$. The mathematical form of this profile may be seen in Pugh (1987), for instance. As in Proctor et al. (1994b), it was used $z_{1}=0.1 \mathrm{~m}$ and a typical value of $20 \mathrm{~m}$ was selected for $z_{2}$. The surface current is a percentage of the wind speed, usually in the range $2 \%-3 \%$. In order to account for Stokes drift, the wind-driven layer speed was increased to $3.5 \%$ of the wind speed (Proctor et al., 1994b). Of course, this is just a parameterization of a very complex non-linear process which is often applied in this type of models. Although the surface current should be deflected to the right (northern hemisphere), this angle is small enough to be safely neglected (Proctor et al., 1994b).

The maximum size of the horizontal step given by the particle due to turbulence, $D_{h}$, is (Proctor et al., 1994b; Hunter, 1987; Periáñez and Elliott, 2002):

$D_{h}=\sqrt{12 K_{h} \Delta t}$

in the direction $\theta=2 \pi R A N$, where $R A N$ is an uniform random number between 0 and 1 . This equation gives the maximum size of the step. In practice, it is multiplied by another independent random number to obtain the real size at a given time and for a given particle. This is required to ensure a simulation of a Fickian diffusion process (Proctor et al., 1994b; Hunter, 1987).

Similarly, the size of the vertical step is (Proctor et al., 1994b; Hunter, 1987; Periáñez and Elliott, 2002):

$D_{v}=\sqrt{2 K_{v} \Delta t}$

given either towards the sea surface or the sea bottom. A new independent uniform random number $R A N$ between 0 and 1 is generated and used to decide the jump direction through the following equation:

$\Delta z=2 \cdot(\operatorname{int}(2 \cdot R A N)-0.5) D_{v}$

In these equations $K_{h}$ and $K_{v}$ are the horizontal and vertical diffusion coefficients respectively and $\Delta t$ is time step. Constant typical values are used for the diffusion coefficients: $K_{v}=1.0 \times 10^{-5} \mathrm{~m}^{2} / \mathrm{s}$ and $K_{h}=10 \mathrm{~m}^{2} / \mathrm{s}$ (Elliott et al., 2001; Mariano et al., 2011; Periáñez et al., 2019). Time step was fixed as $120 \mathrm{~s}$. There is not a stability condition in Lagrangian models equivalent to the Courant-Friedrich-Levy condition (Kowalik and Murty, 1993) of Eulerian models, but it is required to ensure that each particle does not move through a distance that exceeds the grid spacing during each time step. This was satisfied with the selected time step. Linear interpolation in time and space is used to determine the currents at each particle position at the desired time. Note that time interpolation is required only for baroclinic currents, since tidal currents at a given $t$ are determined from an analytical equation in the form of Eq. (3).

Specific processes for oil are described in what follows. Oil droplets have a size distribution so that larger ones tend to remain in the water surface and move in the direction of wind. Smaller ones, in contrast, tend to mix downwards. The diameter of each oil droplet in the simulation is assigned randomly between a minimum and maximum

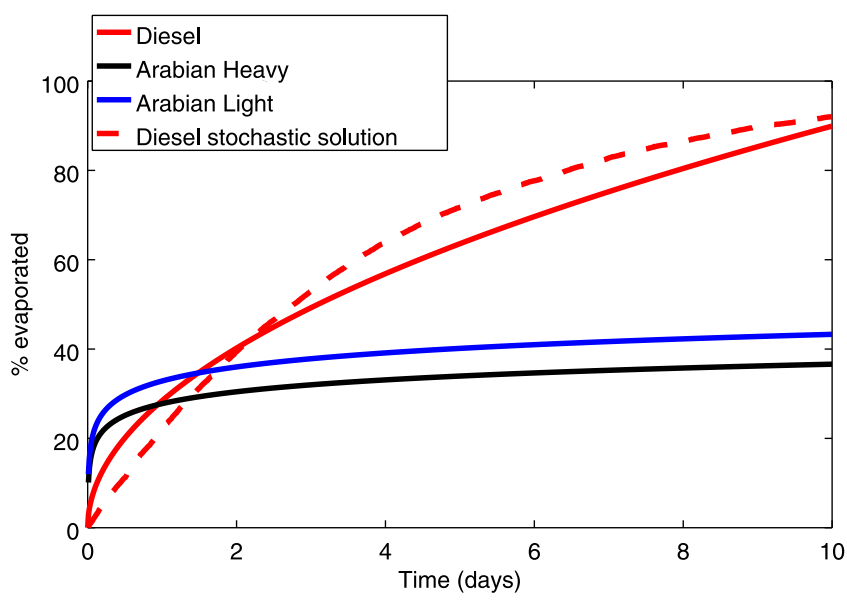

Fig. 1. Evaporation curves for Arabian Heavy and Light oils and regular Diesel at $25{ }^{\circ} \mathrm{C}$ temperature (from equations in Fingas, 2015). The dashed line is the evaporation curve for Diesel as given by the stochastic method described in Section 2.3.

diameter, $d_{\min }-d_{\max }$. Then, the procedure described in Korotenko et al. (2004) and Periáñez and Pascual-Granged (2008) is used to estimate the vertical velocity of oil droplets due to buoyancy forces. Of course, oil droplets have a size distribution. Selecting their sizes between $d_{\min }$ and $d_{\max }$ is just a simplification which minimizes the required input data to run the model. These numbers should represent the quality of the modelled oil, but if they are unknown quoted values may be used. For instance, Proctor et al. (1994b) suggest $d_{\min }=60 \mu \mathrm{m}$ and $d_{\text {max }}=120 \mu \mathrm{m}$.

The model includes the effect of oil evaporation from the surface and decomposition within the water column (because of biodegradation). These processes are treated in a stochastic form based on decomposition and evaporation e-folding times (details may be seen for instance in Proctor et al., 1994b). Only particles which are in a surface layer of $25 \mathrm{~cm}$ thickness may evaporate (Proctor et al., 1994b), while oil at any depth can experience decomposition. The age of each released particle (time since it was released) is calculated. Particles cannot decay after an specified age. This simulates the rapid evaporation which occurs after the release and ensures that some particles remain in the simulation as old and weathered oil (Proctor et al., 1994b).

The e-folding time for evaporation can be deduced from the generic equations proposed for a wide number of oil types by Fingas (2015). These equations provide the fraction of evaporated oil (\% $\mathrm{EV})$ as a function of time and temperature. As examples (Fingas, 2015, table 7.2), for Arabian Heavy oil the equation is :

$\% E V=(2.71+0.045 \cdot T) \ln (t)$

and for regular Diesel it is:

$\% E V=(0.31+0.018 \cdot T) \sqrt{t}$,

where $t$ is time in minutes and $T$ is water temperature in ${ }^{\circ} \mathrm{C}$. The evaporation e-folding times may be estimated from this type of equations. Evaporation curves are represented in Fig. 1 for a temperature of $25^{\circ} \mathrm{C}$ as an example for Diesel and Arabian Light and Heavy. In the case of Diesel, evaporation e-folding time is about 4 days, but it is much longer in the case of Arabians. Decomposition times are usually longer than evaporation ones (Proctor et al., 1994b).

Once an e-folding time $T_{e}$ is known, a probability is defined as (Proctor et al., 1994b):

$p=1-e^{-\Delta t / T_{e}}$,

and an independent uniform random number $R A N$ is generated. If $R A N \leq p$ then the particle is removed from the computation. This procedure gives a realistic representation of the evaporation process. As 
an example, the evaporation of Diesel (e-folding time 4 days) calculated with this method is represented in Fig. 1 as the dashed red line, which can be compared with the solid red line representing Eq. (8).

If a particle reaches the shoreline during a simulation it is considered as "beached" and it does not move anymore. The shore characteristics, as material composition or its slope, are not included in the model as a simplification. Otherwise, a huge amount of information (not always easily available) should be provided as input data. Nevertheless, these simplifications may lead to a overestimation of beaching. The model provides the final positions of particles and the mass of oil per unit of surface over the domain.

\subsection{Computational scheme}

The tidal model was run in advance to calculate and store tidal constituent amplitudes, phases and residuals in files which are read by the transport code during the spill simulations. The tidal model domain extends from $10^{\circ}$ to $30.5^{\circ} \mathrm{N}$ in latitude and from $32^{\circ}$ to $45^{\circ} \mathrm{E}$ in latitude. The same area is used to download HYCOM circulation and it is also used in the oil-spill model. Bathymetry is obtained from NOAA ETOPO1 data, using its on-line tool to design a grid $^{1}$ at a resolution of one minute of arc in both longitude and latitude. The tidal model was started from rest and run over 20 tidal cycles; which is enough to obtain a steadily oscillating solution. It was also run separately for each constituent. Tide elevations were specified along the only open boundary of the domain (south-east) as mentioned before. The component of the current which is parallel to the open boundary was set to zero as usual in tidal computations. As mentioned before, standard tidal analysis was used to calculate the tidal constants for each point in the domain and constituent.

A number of input files are read by the particle-tracking transport code. These are the following:

1. Baroclinic currents previously downloaded from HYCOM website.

2. Tidal amplitudes and phases for the five included constituents, as well as Eulerian residual transports for each of them.

3. Tidal currents and residuals may be individually switched on and off (for instance to evaluate the significance of a given constituent or to make comparisons between them). These switches are provided in a specific file as zeros or ones for each constituent tidal current and residual.

4. Equilibrium arguments and nodal factors for each constituent and for the year of simulation.

5. Bathymetry data with $1 \mathrm{~min}$ of arc resolution from ETOPO1 dataset. This seems a reasonable compromise between resolution and computational requirements, although bathymetric data with higher resolution exist.

6. Release data: date, time, position, depth of release and release magnitude and duration. The duration of the simulation in days is also specified.

7. Oil properties: density, droplet size range and e-folding times.

8. Local (in the area of the accident) wind data if required. This information may be obtained from local observations or weather forecasts.

Of course the wind is not uniform in speed and direction in such a large domain as the Red Sea. However, the local wind in the release area is considered uniform. Local wind data are provided in a file as a number of different "wind episodes" (any number can be used), each one characterized by a wind speed, direction and start and end of the episode in hours after the beginning of the spill. This way timeevolving wind conditions may be used (which can be obtained from weather forecasts). It must be noted that winds are already included

\footnotetext{
1 https://maps.ngdc.noaa.gov/viewers/wcs-client/
}

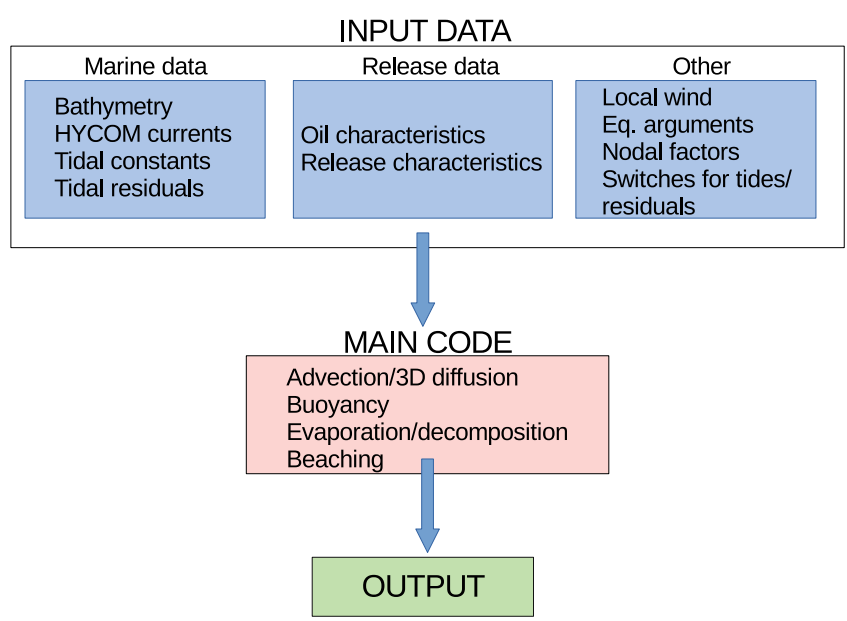

Fig. 2. General scheme of the model working procedure.

in the HYCOM calculations of circulation. However, with the present definition of "wind episodes", we have the opportunity of describing oil transport (in a short temporal scale, thus the spill does not travel very far and the wind may be considered uniform) in case that the accident occurs during a local storm, for instance, which is not described in HYCOM. But specifying this local wind is not a requirement to run the model.

Once all files are read, the transport simulation starts. The concentration of oil is calculated from the number of particles within each grid cell (of ETOPO1 bathymetry) as usual (Periáñez and Elliott, 2002). A general scheme of the model working procedure, summarizing required inputs, is presented in Fig. 2.

\section{Results}

Results of the tidal model will be described before, and compared with observations and previous models. Next, advection processes are analysed and some examples of applications of the spill model are presented.

\subsection{Hydrodynamics}

Tidal charts (corange and cotidal maps) were obtained for the five considered constituents. We only present an example for a semidiurnal tide ( $M_{2}$, Fig. 3) and another (Fig. 4) for the diurnal constituents $K_{1}$. These maps are in close agreement with the previous calculations in Madah et al. (2015), which were carried out with the commercial software Delft3D; Gharbi et al. (2018), with COHERENS model, and Guo et al. (2018): an amphidromic system is apparent in the central Red Sea (around $20^{\circ}$ latitude) in the case of the semidiurnal constituents. This amphidrome is displaced to the south (around $16^{\circ}$ latitude) in the diurnal tides. In general our model reproduces the behaviour of tides in the region. A comparison between the observed and calculated tide amplitudes for the 5 considered constituents may be seen in Fig. 5 .

The calculated amplitude of the tidal current is shown in Fig. 6 for the $M_{2}$ constituent as an example. The largest amplitudes are found in the area of BeM Strait; but also in areas near the east shore, where currents increase their magnitudes in the straits between the many small islands. Significant currents are observed in the Gulf of Suez as well. The small tidal currents calculated in the central Red Sea are in agreement with the observations in Churchill et al. (2014), which indicate values below $0.04 \mathrm{~m} / \mathrm{s}$.

Two examples of baroclinic circulation, as downloaded from HYCOM model website, may be seen in Fig. 7, corresponding to the end of January and July. Thus, they are representing winter and summer conditions. These conditions are clearly different: the flow is mainly 
Tide amplitude (m)

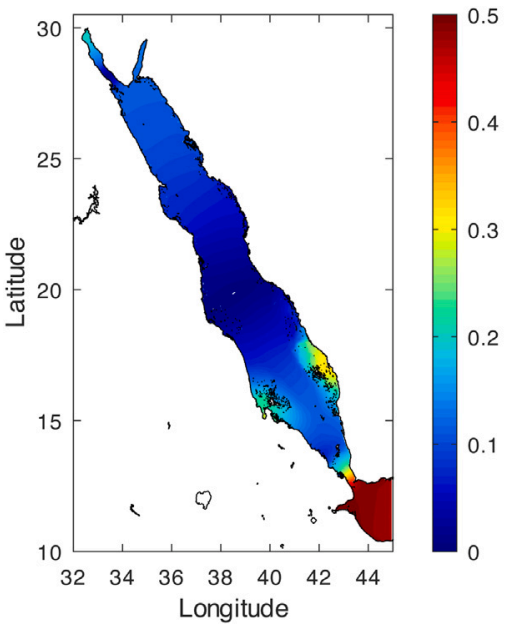

Phase (deg)

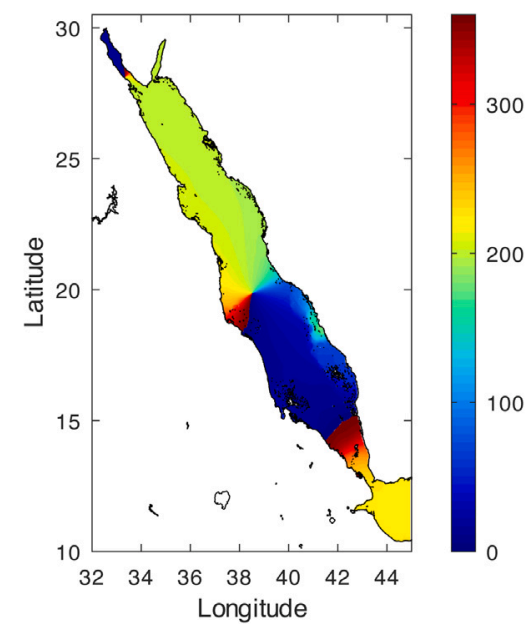

Fig. 3. Calculated chart for the $M_{2}$ tide.
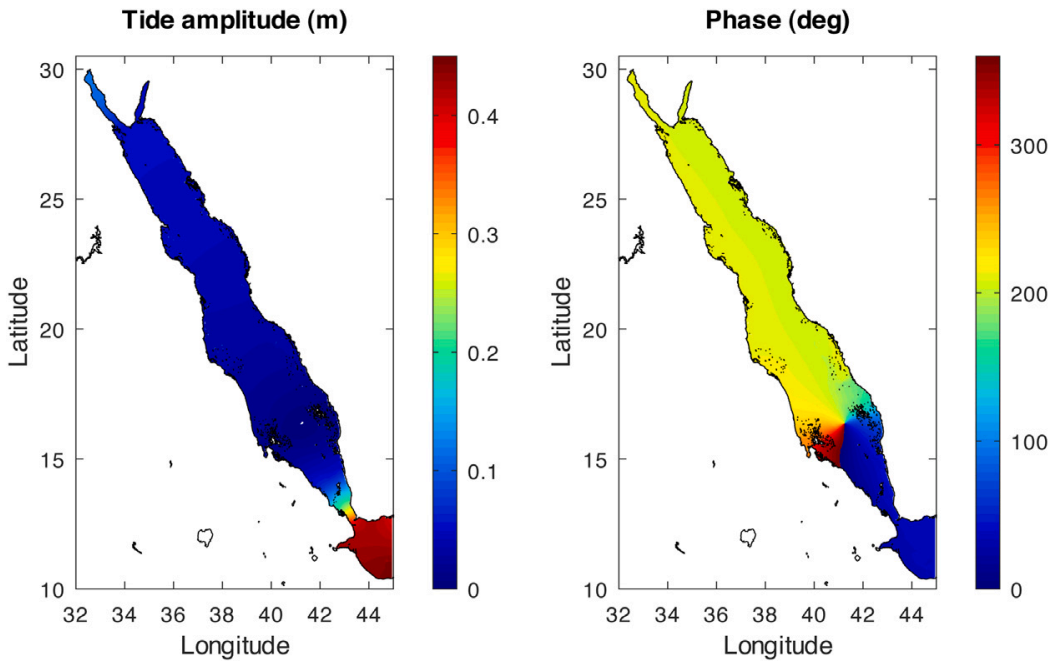

Fig. 4. Calculated chart for the $K_{1}$ tide.
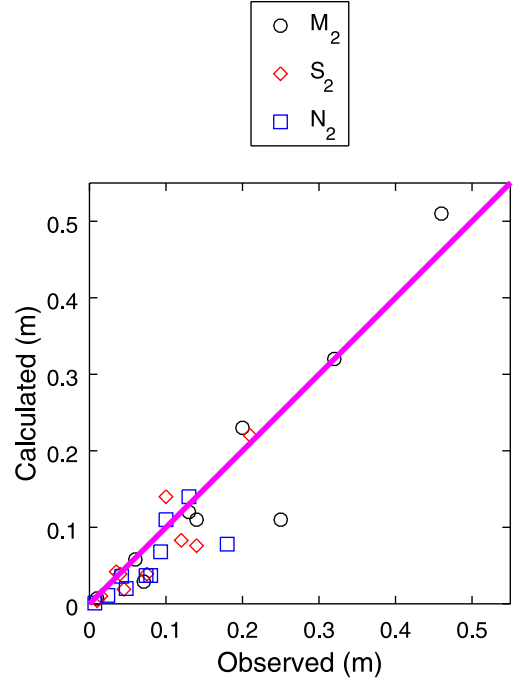
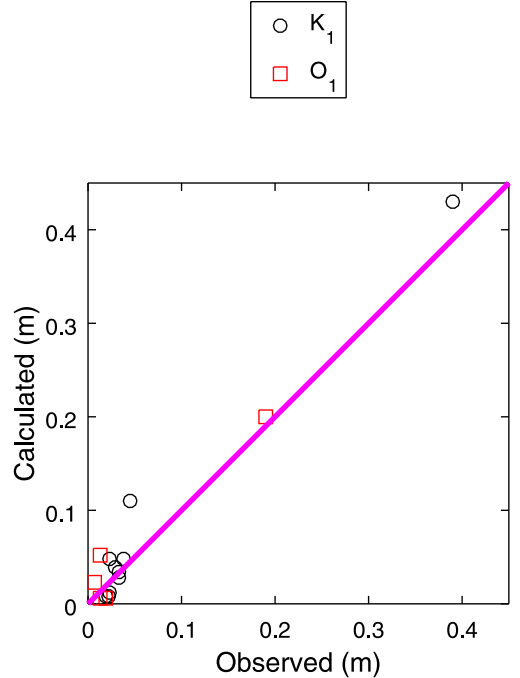

Fig. 5. Comparisons between calculated and observed tide amplitudes for several locations in the Red Sea and for semidiurnal (left) and diurnal (right) tides. 


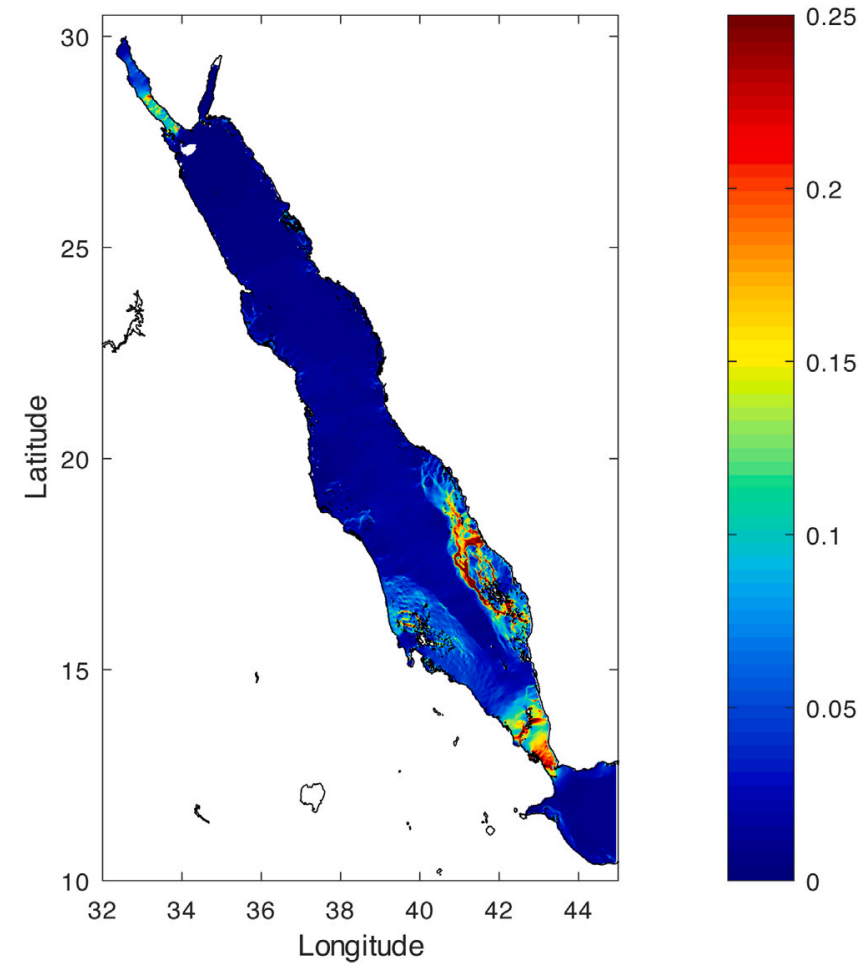

Fig. 6. Calculated amplitude of the $M_{2}$ tidal current (m/s).

directed to the north along the east side of the sea in winter. This circulation essentially disappears in summer, when the flow reverses and is directed to the south in BeM Strait. This effect, due to monsoon reversal, is known since a long time (Patzert, 1974).

\subsection{Transport processes}

Some numerical experiments were initially carried out to evaluate the relative significance of tidal currents, tidal residuals and baroclinic

\section{January}

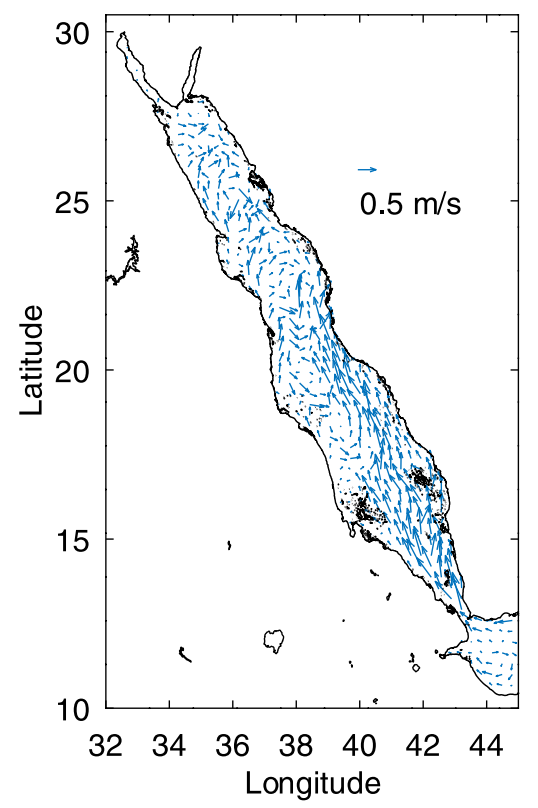

circulation in the transport of contaminants in the Red Sea. An instantaneous release of a passive tracer (only suffers advection and diffusion) was simulated in four different areas of the sea. Six simulations were carried out for each site: one included the three sources of currents (tidal currents, tidal residuals and baroclinic circulation), in another one tidal currents were excluded and the third one excluded both tidal currents and tidal residuals. Finally, these simulations were carried out for a typical situation in winter (February 1st, 2020) and another in summer (August 1st, 2020). The positions of particles 30 days after the release were obtained.

Results of the six simulations for a release occurring in the region near BeM Strait are presented in Fig. 8. First, it may be seen that in summer particles travel a short distance towards the south, but in winter there is significant transport to the north. There are essentially not differences between the three hydrodynamic configurations in summer, thus baroclinic circulation is dominant. If tides are removed in the winter simulation, then northwards transport is reduced. This indicates that tidal mixing is relevant in this area during winter.

Results of simulations for a release in the central Red Sea may be seen in Fig. 9. Again, particles travel a short distance towards the south in summer, but in winter there is significant transport to the north. The different hydrodynamic configurations do not lead to noticeable differences in results. Thus, baroclinic circulation is clearly dominant. Similar conclusions can be obtained in the case of a release occurring near the east shore (Fig. 10). However, in this case, differences between summer and winter conditions are not as significant as in previous cases. Only a higher transport towards the central sea is observed during summer. In contrast, transport is mainly directed to the north in winter.

The last experiment results, for a release in the northern Red Sea, are presented in Fig. 11. Again there are significant differences between winter and summer conditions. There is a weak circulation in winter, which leads to a short travel distance of particles towards the south. However, in summer there is a significant transport towards the south, but then particles enter in a gyre which direct them to the north again. Some particles reach the northeast shore of the Red Sea.

As general conclusions, it may be said that tidal residuals constitute a weak forcing agent in transport processes within the Red Sea. Tides are significant only in the region near BeM Strait, where actually tidal

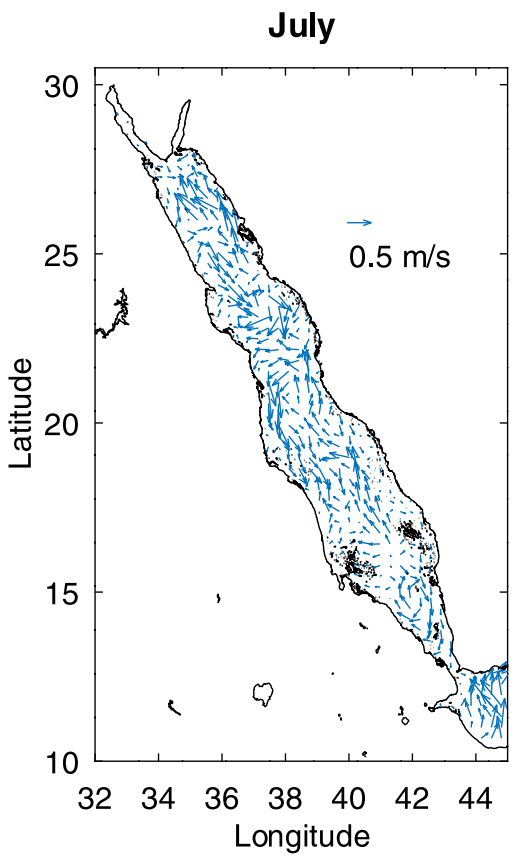

Fig. 7. Baroclinic currents as calculated by HYCOM model for the end of January and July. Only one of each 16 vectors are drawn for more clarity. 


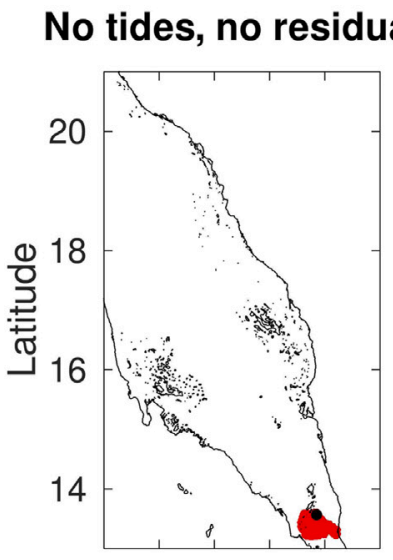

394041424344

No tides, no residuals

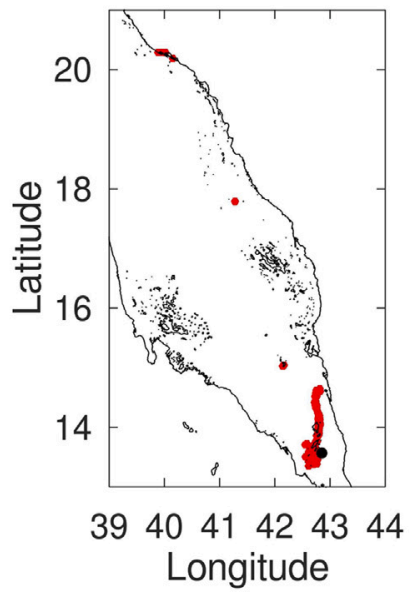

Only residuals

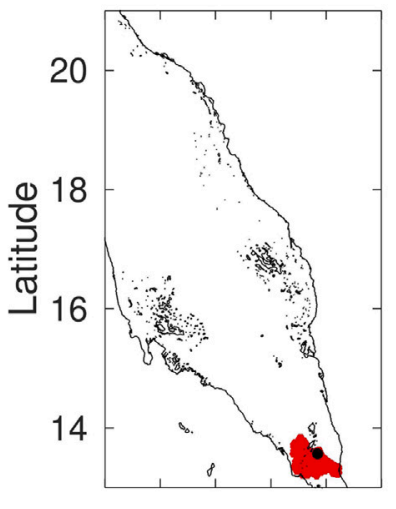

394041424344

\section{Tides and residuals}

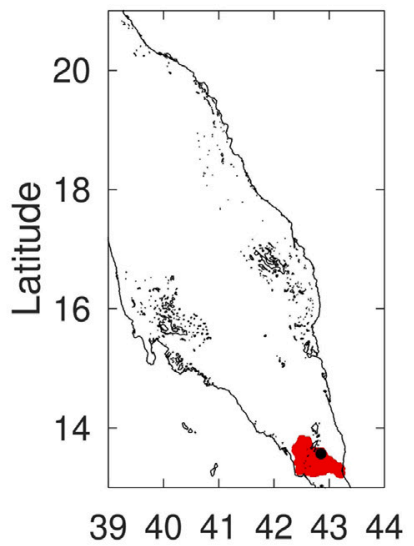

Only residuals

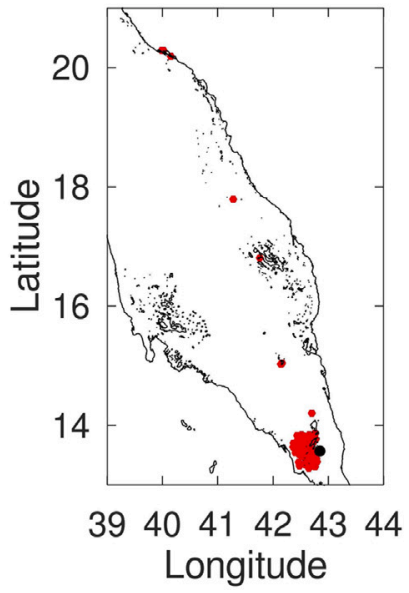

Tides and residuals

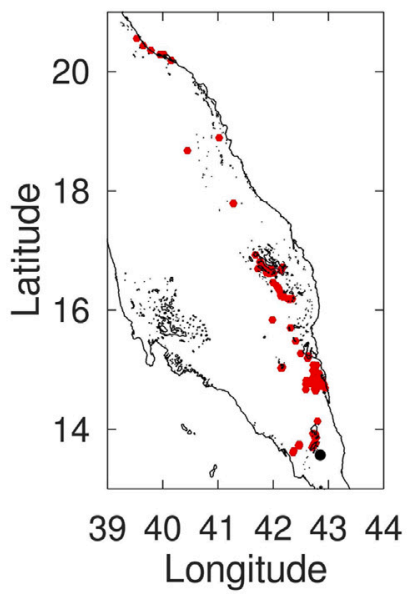

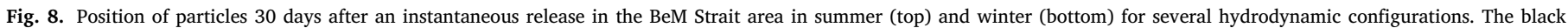
dot is the release point.

currents are stronger (Fig. 6) and thus enhance initial mixing of the spill. Clearly, baroclinic circulation is the dominant forcing of transport within most of the sea, both for typical winter and summer conditions.

The oil transport model was compared with the results of the simulation presented in Nasr and Smith (2006). It consisted of a hypothetical surface release of Arabian Light crude occurring in the Gulf of Suez in a point located in the shipping path line. The accident occurred on July 29th and only one day was simulated in Nasr and Smith (2006), consequently the same time was used. Wind data was provided in Nasr and Smith (2006) as well, obtained from the Egyptian Meteorological Authority. Wind was changing along the simulation time, both in speed and direction, thus this simulation additionally allowed us to test our method to specify local wind conditions. Light crude oil density was fixed as $830 \mathrm{~kg} / \mathrm{m}^{3}$ (Hollebone, 2015). Evaporation and decomposition e-folding times are long in comparison with the simulated time and thus these processes were neglected in the present simulation. Results of our simulation may be seen in Fig. 12 (top), which are in good agreement with those of Nasr and Smith (2006) - their figure 3. The spill travels about $20 \mathrm{~km}$ in southeast direction and the Egyptian shore is contaminated along several $\mathrm{km}$ (red dots in Fig. 12, which indicate beached particles). The same simulation was repeated excluding the local wind and considering only baroclinic currents. These results are presented in Fig. 12 (bottom), which show a totally different transport pattern. Thus, although atmospheric forcing is included within HYCOM ocean model, the specification of local wind conditions may be required in some cases, specially in coastal locations where the resolution of the ocean model used is not high enough.
Ahmed et al. (2012a) simulated the transport of oil in Sudanese coastal waters after some hypothetical releases in winter and summer. They used mean prevailing wind directions in each season (thus constant wind was assumed) and did not provide details on the release date and how water currents were specified; only that "they are provided in map forms that identifies the spatial variations in the water velocities" (sic). We have compared our model with results for their winter experiment (previous simulation in Fig. 12 was done for summer). We also assumed that the release occurred on December 30th (since a date was not provided as mentioned before). Simulation time was half a day, thus evaporation and decomposition were neglected, and Sudanese oil with density $854 \mathrm{~kg} / \mathrm{m}^{3}$ was spilled. Results of our simulation may be seen in Fig. 13, which shows that about $10 \mathrm{~km}$ of shore was contaminated with oil. Our results generally are in agreement with Ahmed et al. (2012a).

An oil spill occurred on October 11, 2019, in the point with coordinates $38.33^{\circ} \mathrm{E}, 21.13^{\circ} \mathrm{N}$ after the explosion of the oil tanker Sabiti. The resulting spill was simulated, and results were compared with a satellite picture taken two days after the incident (see Fig. 14). The comparison is quite limited because the spill most likely occurred as a continuous release, but there is not information about timing and release rates and thus we simulated a single event (instantaneous release). Nevertheless, the model indicates that there is some transport to the north of the spill point, although most of the oil travels to the south. This branch is curved to the east due to the presence of an eddy. The satellite image shows that the transport is directed more in northwest and southeast directions rather than north and south, but the overall picture provided by the model seems realistic taking into account the limitations of 

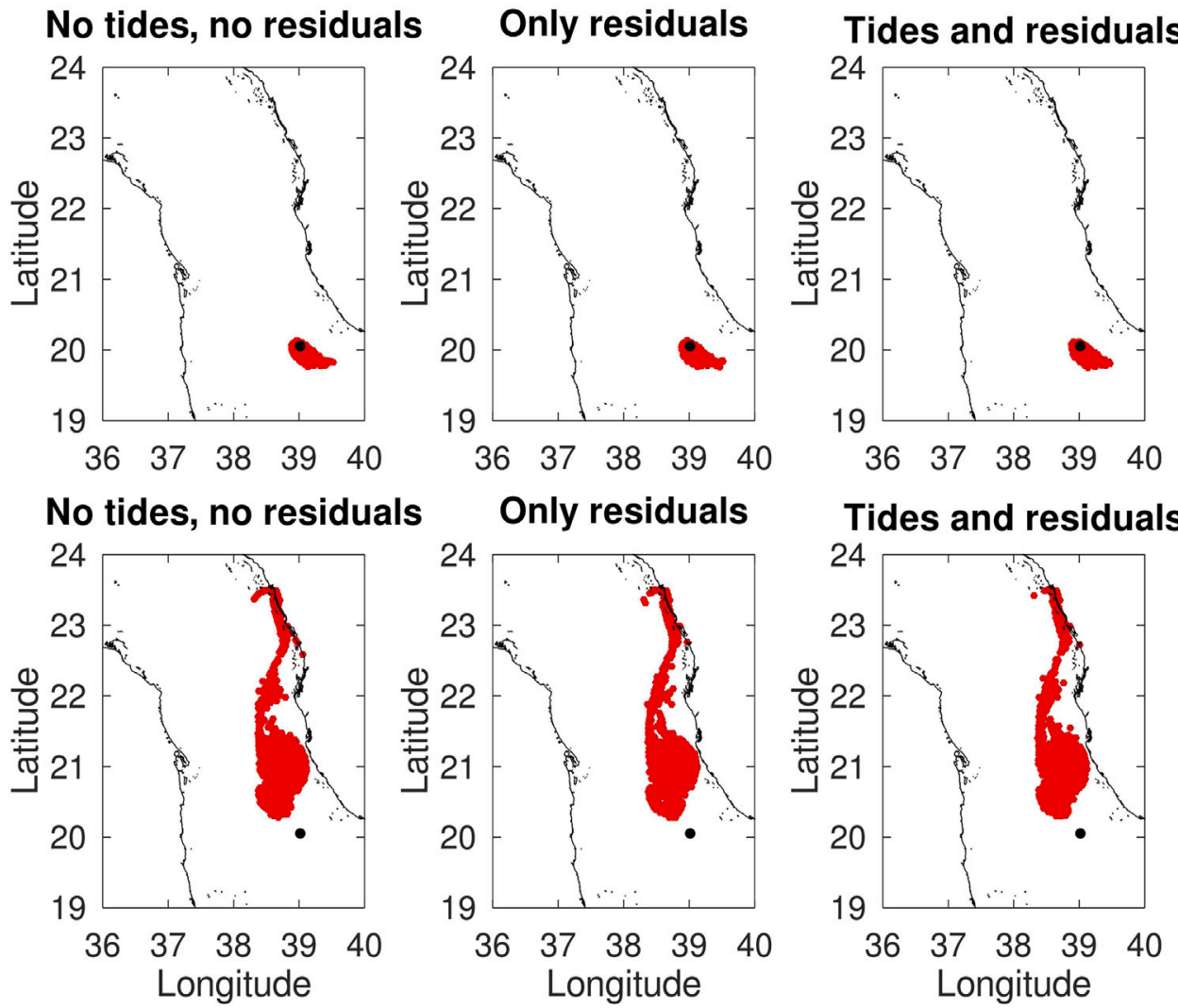

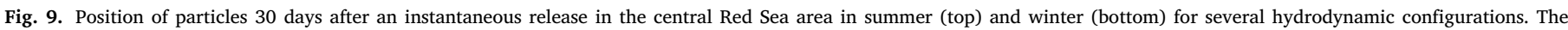
black dot is the release point.
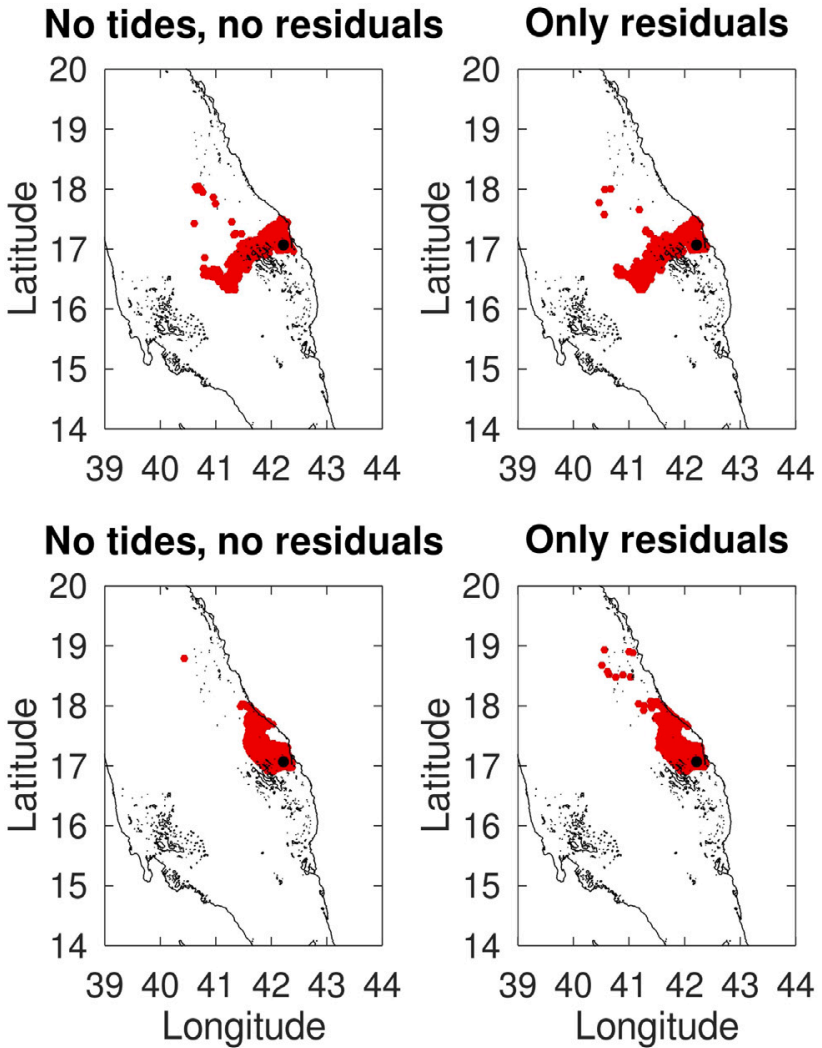

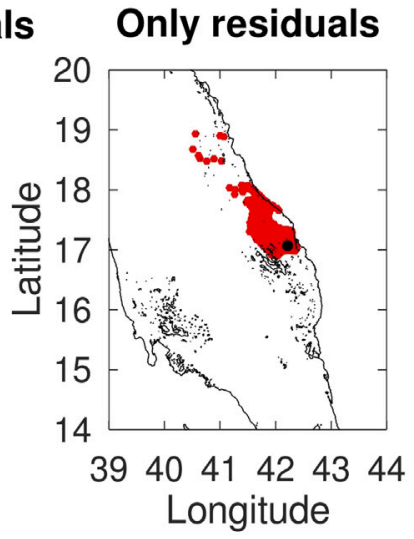

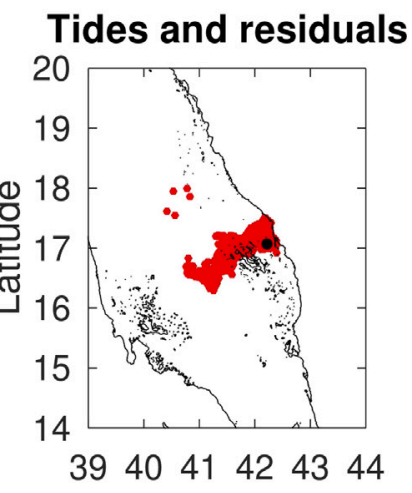

Tides and residuals

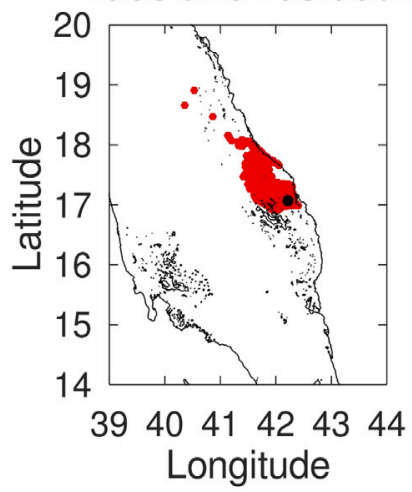

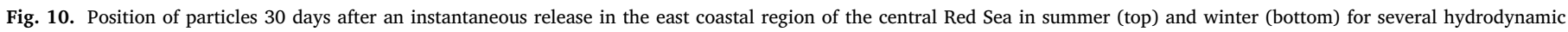
configurations. The black dot is the release point. 


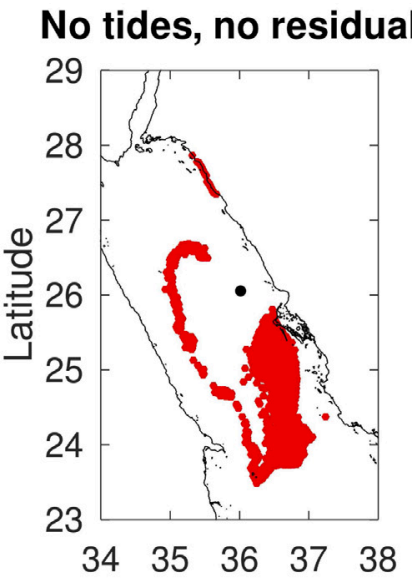

Only residuals

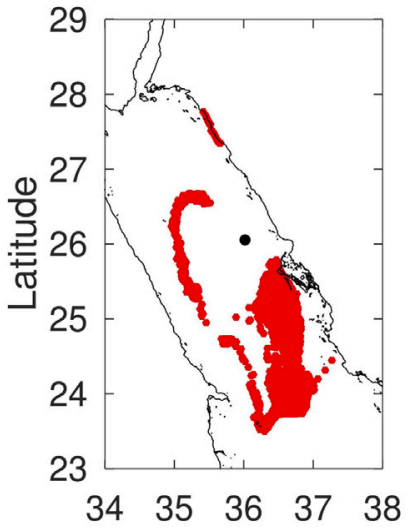

No tides, no residuals

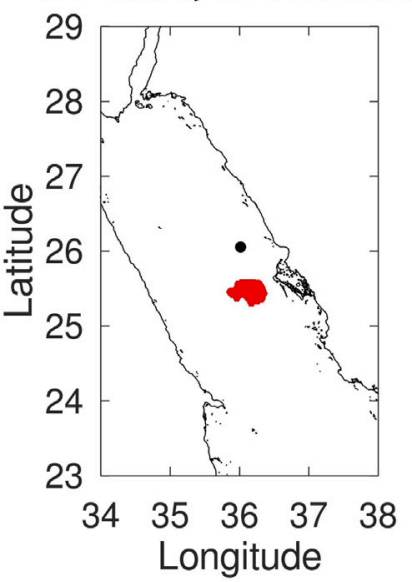

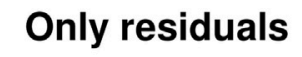

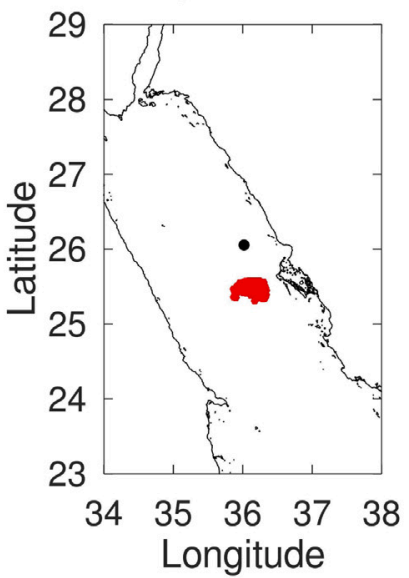

Tides and residuals

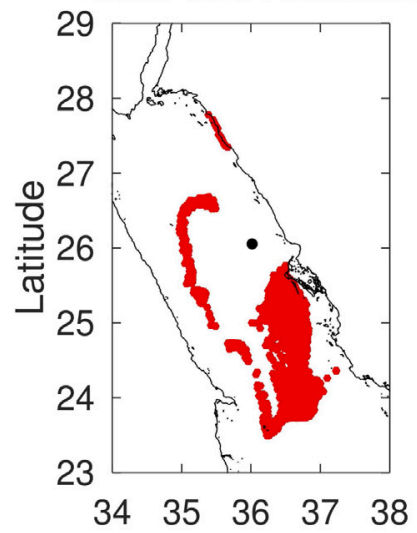

Tides and residuals

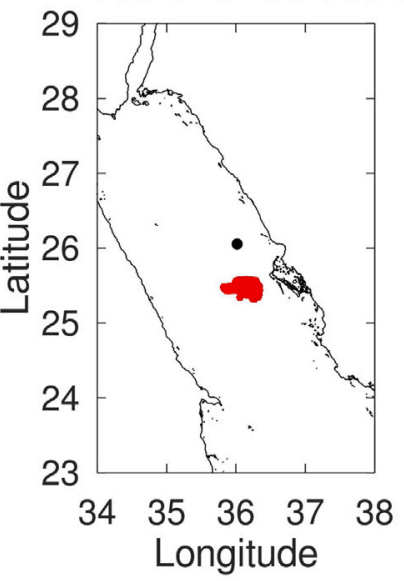

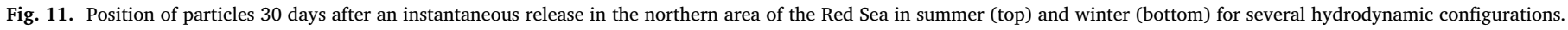
The black dot is the release point.

the simulation. Only baroclinic circulation was used and some generic parameters for oil (density $940 \mathrm{~kg} / \mathrm{m}^{3}$, particle size range $100-300 \mu \mathrm{m}$, evaporation and decomposition neglected due to the short simulation time) were used.

A hypothetical oil spill was additionally simulated to show the functioning of the model at longer temporal scales than simulations shown before. A hypothetical heavy oil was used for the simulations, with evaporation and decomposition e-folding times fixed as 150 days and 400 days respectively, since the last process typically has a scale of years (Mariano et al., 2011). Density of heavy oil is in the range of 880 to $1000 \mathrm{~kg} / \mathrm{m}^{3}$ (Hollebone, 2015), and an intermediate value of $940 \mathrm{~kg} / \mathrm{m}^{3}$ was used here. Oil droplet size is in the range of 100 to $300 \mu \mathrm{m}$. This selection allows studying particles which will mainly stay close to the surface (Mariano et al., 2011) and consequently will be more efficiently transported by currents. The spill occurred during spring in this case (April 15th) in the central Red Sea, at the surface, and tides were not included since their effects in this area are not significant as shown before. However, tidal residuals were included. Results of a 20 day long simulation can be seen in Fig. 15. The spill is directed to the north by baroclinic currents and during this transit some particles are beached in the eastern shore, approximately at $20^{\circ} \mathrm{N}$ latitude. An eddy turns particles back to the south and some oil reaches the islands located close to the western shore at about $19^{\circ} \mathrm{N}$. A balance indicates that $14.5 \%$ of oil was beached, $70.0 \%$ remains in water and $15.5 \%$ has decayed or evaporated after 20 days. If evaporation and decomposition were neglected, then the fraction of oil remaining in water is $84.6 \%$; and $15.4 \%$ is beached. Given the used droplet size range (see above), all the oil remains in the surface, within a $5 \mathrm{~cm}$ thick layer. This thickness increases to $44 \mathrm{~cm}$ if droplets are in the range $60-120 \mu \mathrm{m}$. Even smaller droplets $(30-60 \mu \mathrm{m})$ lead to a penetration of $1.9 \mathrm{~m}$.

The same simulation was repeated but with the release occurring in fall (October 15th). Results, which may be seen in Fig. 16, are significantly different to those of Fig. 15. Again the oil is initially directed to the north, but the change of direction to the south occurs at a shorter distance from the release point than before, indicating that the eddy is displaced to the south in this season. Also, the coast is not contaminated. As another example, a map showing the final oil amount per unit surface $\left(\mathrm{kg} / \mathrm{m}^{2}\right)$ in this simulation, resulting from the particle distribution shown in Fig. 16, is presented in Fig. 17. These concentrations were calculated over a surface water layer operationally defined as $1 \mathrm{~m}$ thick. It was assumed that $10^{6} \mathrm{~kg}$ of heavy oil were released (1064 $\mathrm{m}^{3}$, since oil density is $940 \mathrm{~kg} / \mathrm{m}^{3}$ as mentioned before).

\section{Conclusions}

A Lagrangian model which simulates the transport of oil spills in the Red Sea was developed. Water circulation was obtained from two sources: tides and tidal residuals were computed with a two dimensional barotropic model and baroclinic circulation was obtained from HYCOM ocean model, downloaded from its web site. The transport model includes advection by currents and local, episodic, winds, three-dimensional diffusion and specific processes for oil, as buoyancy, evaporation, decomposition and beaching.

The transport model was initially applied to passive particles (only suffering advection and diffusion) to evaluate the relative significance 

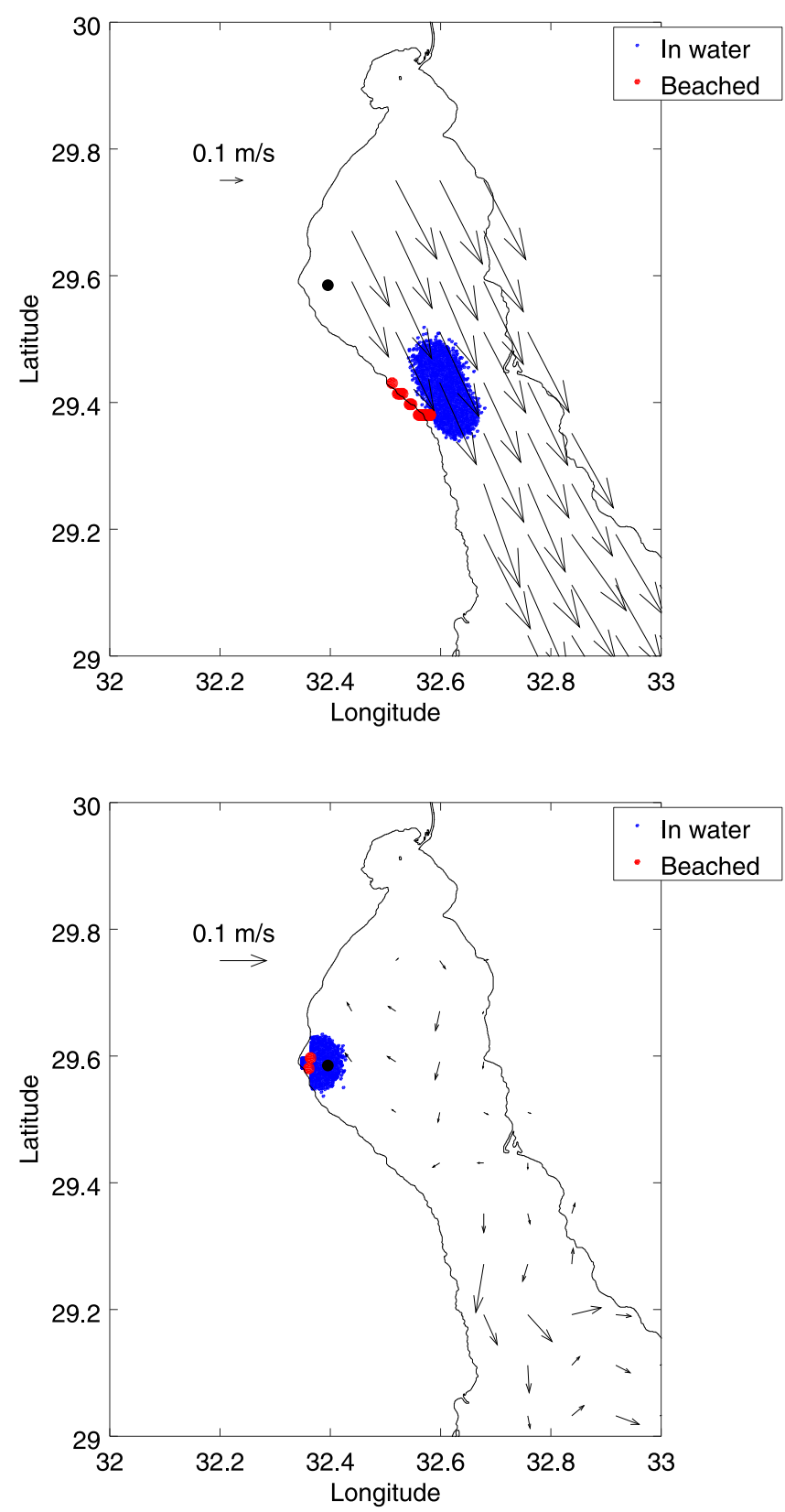

Fig. 12. Position of particles in water and beached for the release in the Gulf of Suez. The black dot is the release position and vectors show surface circulation. Results are shown for baroclinic circulation plus local wind forcing (top) and if the local wind is omitted (bottom).

of the different components of the water currents over several areas of the Red Sea. It was found that tidal residuals have a very weak effect in transport processes within the Red Sea. Tides are significant only in the region near BeM Strait. Baroclinic circulation clearly is the dominant forcing of transport within the sea, both for typical winter and summer conditions.

The oil spill model was first compared with results of two simulations previously carried out by independent authors. Results were in general in good agreement. This work, however, constitutes a further step in oil spill modelling in the Red Sea for decision-making after an accidental spill, since the only input required is the oil properties and spill characteristics (location, time, date, magnitude) in addition to a local wind forecast, if required. Detailed water circulation data are previously stored in files which are read by the transport code and

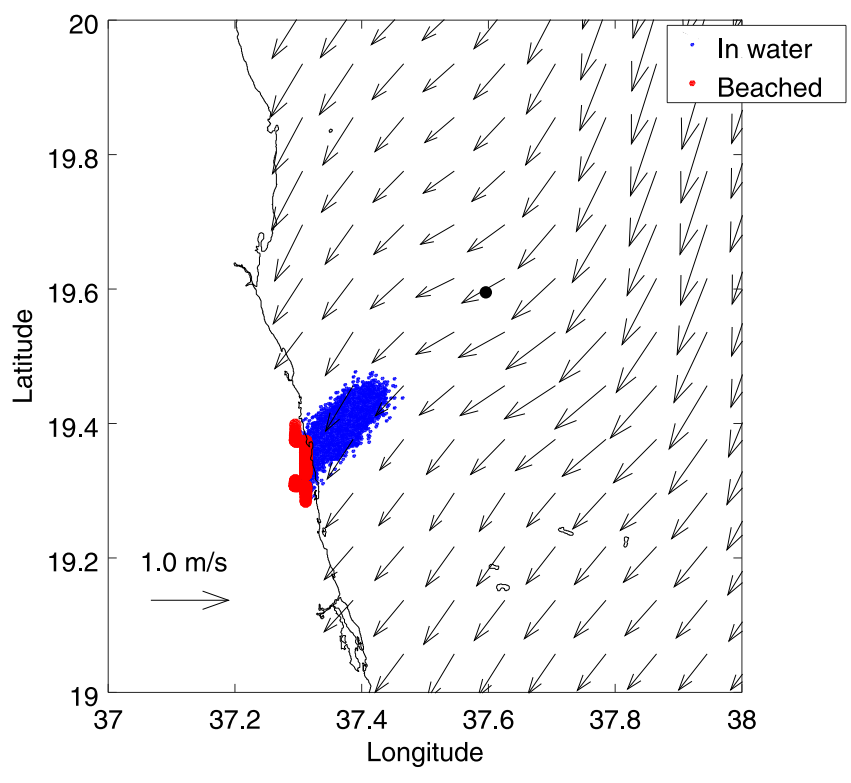

Fig. 13. Position of particles in water and beached for a release in Sudanese coastal waters. The black dot is the release position and vectors show surface circulation.

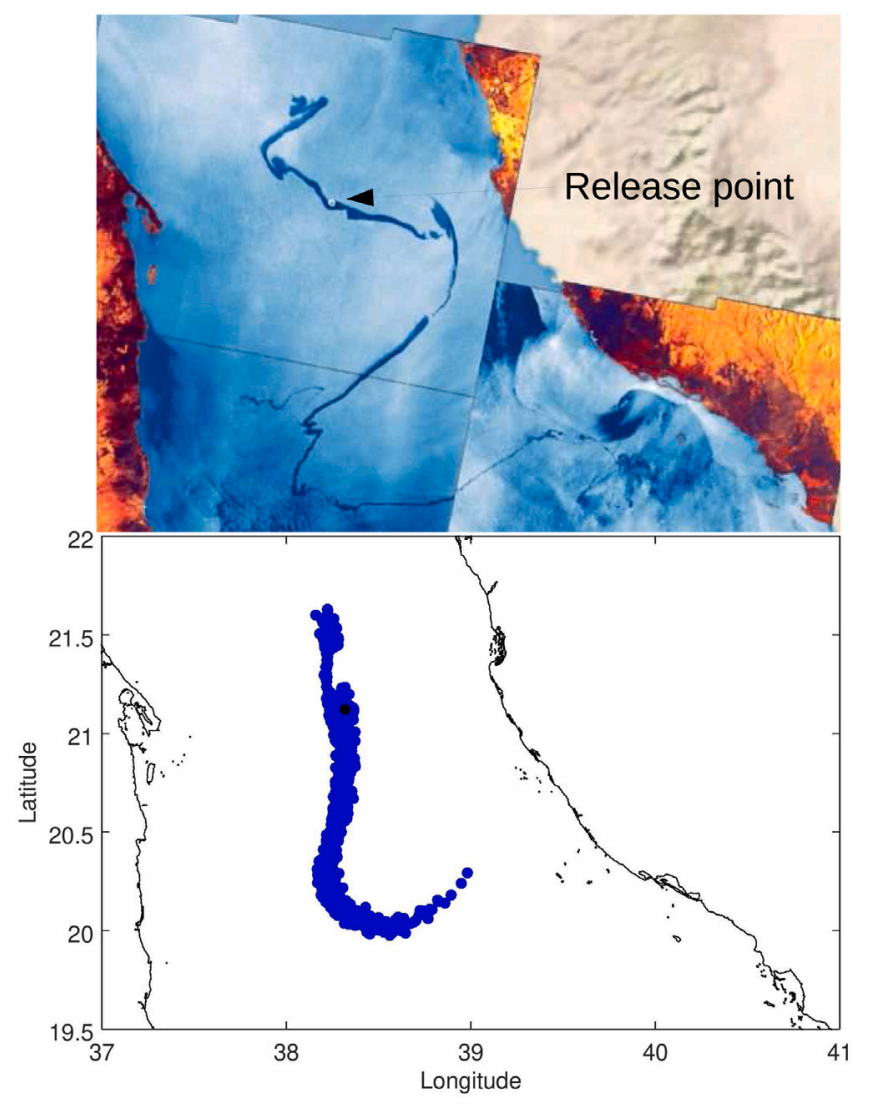

Fig. 14. Position of particles in water for the oil spill on October 11, 2019. The black dot is the release position. A satellite picture of the spill taken two days later is shown in the top panel, where the release point is indicated as well.

Source: Image from the European Space Agency (http://www.esa.int/).

includes daily currents from a widely tested ocean model (HYCOM) plus calculated tidal currents and residuals for the most significant constituents. For instance, in the model by Nasr and Smith (2006) a map describing circulation "was developed in this work for the summer 


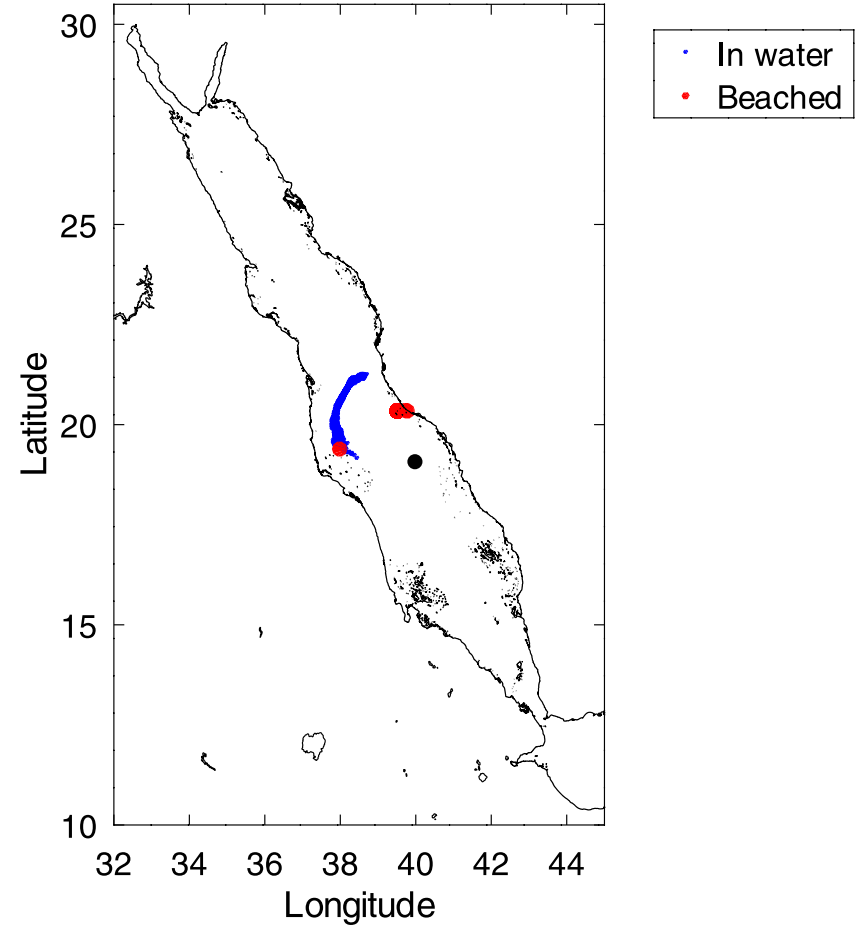

Fig. 15. Position of particles in water and beached 20 days after a release in spring in the central Red Sea. The black dot is the release position.

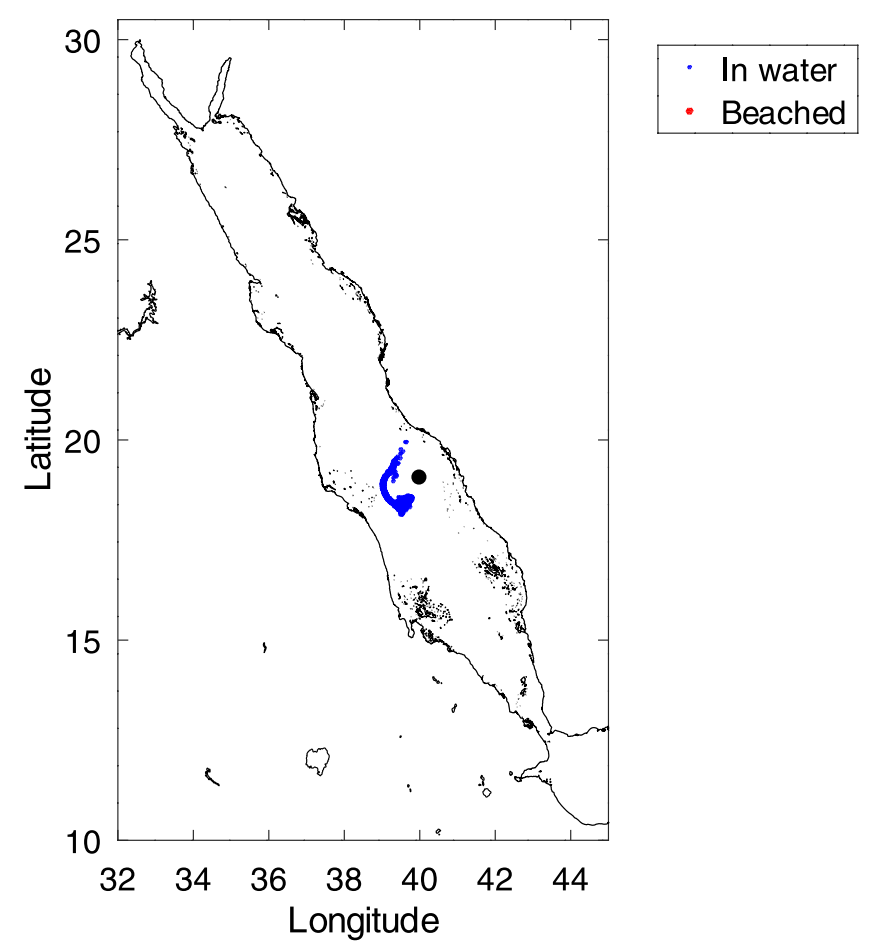

Fig. 16. Position of particles in water and beached 20 days after a release in fall in the central Red Sea. The black dot is the release position.

season by integration of data from the National Oil Spill Contingency Plan, observations from numerous site surveys, and assistance and confirmation by sea captains" (sic). In addition it is a local model for the Gulf of Suez, while the present model describes the whole Red Sea. A similar method to that of Nasr and Smith (2006) seems to have been

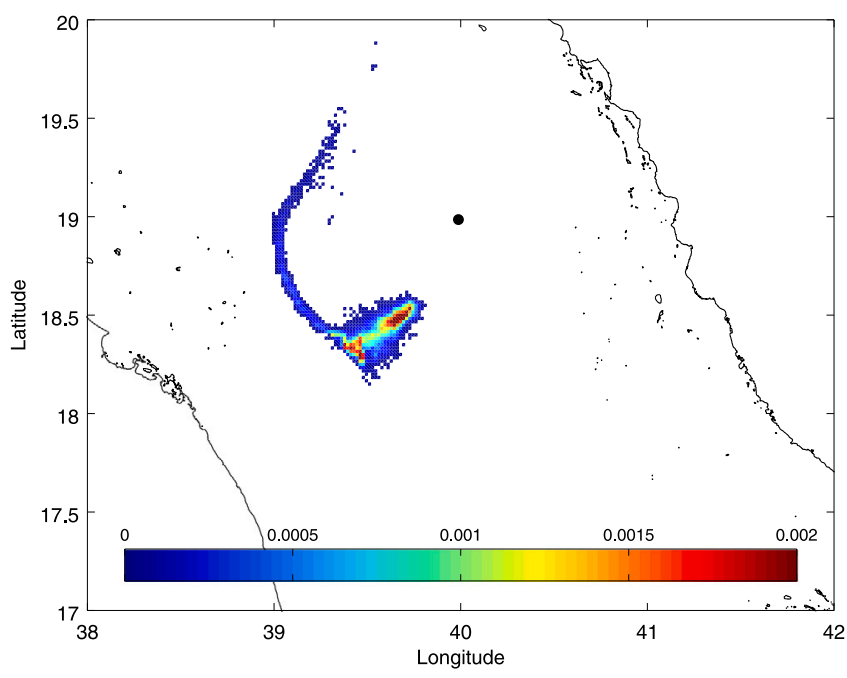

Fig. 17. Oil distribution $\left(\mathrm{kg} / \mathrm{m}^{2}\right)$ in the surface (operationally considered as $1 \mathrm{~m}$ thick) resulting of the particle positions shown in Fig. 16. The black dot is the release location.

applied by Ahmed et al. (2012a) to obtain water circulation, at a local scale as well.

The application of the present model requires a few minutes to modify input data files and running time is relatively fast on a desktop computer. A 20 day long simulation requires about $110 \mathrm{~s}$ if tides are not included and about $28 \mathrm{~min}$ if they are, on a PC with $3.20 \mathrm{GHz}$ processor working with Ubuntu 18.04 operating system. 20000 particles were used in the simulations presented in the paper. This number may be increased (50000 were also tested), but any significant change in results was not found in the temporal frames explored here.

A significant number of approximations and simplifications were included in the model. Thus few parameters are required, which should be selected to represent the quality of the simulated oil. Generic or quoted values may be used if specific ones are not available. However, in the author opinion, the described model represents a compromise between the level of detail in the description of the transport processes and (a) how easily the model is prepared for a simulation; (b) short running times even on a PC. The model can be adapted to run in any other place if a description of water circulation from HYCOM or other ocean model can be obtained. We are presenting a strategy to achieve this goal.

\section{Declaration of competing interest}

The authors declare that they have no known competing financial interests or personal relationships that could have appeared to influence the work reported in this paper.

\section{References}

Ahmed, M.G., Elhassan, B.M., Bashar, K.E., 2012a. Modelling of oil spill trajectory and fate in Sudanese Red Sea coastal water. J. Sci. Technol. 13, 64-73.

Ahmed, M.G., Elhassan, B.M., Bashar, K.E., 2012b. Modeling of oil spill in the sudanese red sea coastal water. Sudan Eng. Soc. J. 58, 45-53.

Bleck, R., 2001. An oceanic general circulation model framed in hybrid isopycnic-cartesian coordinates. Ocean Model. 4, 55-88.

Bourgault, D., Cyr, F., Dumont, D., Carter, A., 2014. Numerical simulation of the spread of floating passive tracer released at the Old Harry Prospect. Environ. Res. Lett. 9, 054001.

Carracedo, P., Torres-López, S., Barreiro, M., Montero, P., Balseiro, C.F., Penabad, E., Leitao, P.C., Pérez-Muñuzuri, V., 2006. Improvement of pollutant drift forecast system applied to the Prestige oil spills in Galicia Coast (NW of Spain): development of an operational system. Mar. Pollut. Bull. 53, 350-360.

Churchill, J.H., Lentz, S.J., Farrar, J.T., Abualnaja, Y., 2014. Properties of Red Sea coastal currents. Cont. Shelf Res. 78, 51-61. 
Cushman-Roisin, B., Beckers, J.M., 2011. Introduction to Geophysical Fluid Dynamics. Elsevier.

Díaz, B., Pavón, A., Gómez-Gesterira, M., 2008. Use of a probabilistic particle tracking model to simulate the prestige oil spill. J. Mar. Syst. 72, 159-166.

Dyke, P.P.H., 2001. Coastal and Shelf Sea Modelling. Kluwer Academic Publishers.

Elliott, A.J., Clarke, S., 1998. Shallow water tides in the firth of forth. Hydrogr. J. 87, 19-24.

Elliott, A.J., Wilkins, B.T., Mansfield, P., 2001. On the disposal of contaminated milk in coastal waters. Mar. Pollut. Bull. 42, 927-934.

Fingas, M., 2015. Oil and petroleum evaporation. In: Fingas, M. (Ed.), Handbook of Oil Spill Science and Technology. John Wiley \& Sons, pp. 207-223.

Gharbi, S.H., Albarakati, A.M., Alsaafani, M.A., Saheed, P.P., Alraddadi, T.M., 2018. Simulation of tidal hydrodynamics in the Red Sea using COHERENS. Reg. Stud. Mar. Sci. 22, 49-60.

Guo, D., Kartadikaria, A., Zhan, P., j, Xie, Li, M., Hoteit, I., 2018. Baroclinic tides simulation in the Red Sea: comparisons to observations and basic characteristics. J. Geophys. Res. Ocean. 123, http://dx.doi.org/10.1029/2018JC013970.

Hollebone, B.P., 2015. Oil physical properties: measurement and correlation. In: Fingas, M. (Ed.), Handbook of Oil Spill Science and Technology. John Wiley \& Sons, pp. 39-50.

Hunter, J.R., 1987. The application of Lagrangian particle tracking techniques to modelling of dispersion in the sea. In: Noye, J. (Ed.), Numerical Modelling, Applications to Marine Systems. Elsevier, North-Holland, pp. 257-269.

Jordi, A., Ferrer, M.I., Vizoso, G., Orfila, A., Basterretxea, G., Casas, B., Alvarez, A., Roig, D., Garau, B., Martínez, M., Fernández, V., Fornés, A., Ruiz, M., Fornós, J.J., Balaguer, P., Duarte, C.M., Rodríguez, I., Alvarez, E., Onken, R., Orfila, P., Tintoré, J., 2006. Scientific management of Mediterranean coastal zone: a hybrid ocean forecasting system for oil spill and and search and rescue operations. Mar. Pollut. Bull. 53, 361-368.

Korotenko, K.A., Mamedov, R.M., Kontar, A.E., Korotenko, L.A., 2004. Particle-tracking method in the approach for prediction of oil slick transport in the sea: modelling oil pollution resulting from river input. J. Mar. Syst. 48, 159-170.

Kowalik, Z., Murty, T.S., 1993. Numerical Modelling of Ocean Dynamics. World Scientific, Singapore.

Lynch, D.R., Greenberg, D.A., Bilgili, A., Mcgillicuddy, D.J., Manning, J.P., Aretxabaleta, A.L., 2015. Particles in the Coastal Ocean. Theory and Applications. Cambridge University Press, NY.

Madah, F., Mayerle, R., Bruss, G., Bento, J., 2015. Characteristics of tides in the Red Sea region, a numerical model study. Open J. Mar. Sci. 5, 193-209.

Maderich, V., Brovchenko, I., Jung, K.T., 2012. Oil spreading in instantaneous and continuous spills on rotating earth. Environ. Fluid Mech. 12, 361-378.

Mariano, A.J., Kourafalou, V.H., Srinivasa, A., Kang, H., Halliwell, G.R., Ryan, E.H., Roffer, M., 2011. On the modeling of the 2010 Gulf of Mexico oil spill. Dyn. Atmos. Oceans 52, 322-340.
Nasr, P., Smith, E., 2006. Simulation of oil spills near environmentally sensitive areas in Egyptian coastal waters. Water Environ. J. 20, 11-18.

Patzert, W.C., 1974. Wind-induced reversal in Red Sea circulation. Deep Sea Res. Oceanogr. Abstr. 21, 109-121.

Periáñez, R., 2007. Chemical and oil spill rapid response modelling in the strait of Gibraltar-Alborán Sea. Ecol. Model. 207, 210-222.

Periáñez, R., 2009. Environmental modelling in the Gulf of Cadiz: heavy metal distributions in water and sediments. Sci. Total Environ. 407, 3392-3406.

Periáñez, R., 2012. Modelling the environmental behavior of pollutants in Algeciras Bay (south Spain). Mar. Pollut. Bull. 64, 221-232.

Periáñez, R., Abril, J.M., 2014. A numerical modelling study on oceanographic conditions in the former Gulf of Tartessos (SW Iberia): tides and tsunami propagation. J. Mar. Syst. 139, 68-78.

Periáñez, R., Bezhenar, R., Brovchenko, I., Jung, K.T., Kamidara, Y., Kim, K.O., Kobayashi, T., Maderich, V., Liptak, L., Min, B.I., Suh, K.S., 2019. Fukushima ${ }^{137} \mathrm{Cs}$ releases dispersion modelling over the Pacific Ocean. Comparisons of models with water, sediment and biota data. J. Environ. Radioact. 198, 50-63.

Periáñez, R., Elliott, A.J., 2002. A particle tracking method for simulating the dispersion of non conservative radionuclides in coastal waters. J. Environ. Radioact. 58, 13-33.

Periáñez, R., Pascual-Granged, A., 2008. Modelling surface radioactive, chemical and oil spills in the Strait of Gibraltar. Comput. Geosci. 34, 163-180.

Periáñez, R., z, M.Casas-Ruí., Bolívar, J.P., 2013. Tidal circulation, sediment and pollutant transport in Cádiz Bay (SW Spain): a modelling study. Ocean Eng. 69, 60-69.

Pickard, G.L., Emery, W.J., 1982. Descriptive Physical Oceanography. An Introduction. Pergamon Press.

Proctor, R., Elliott, A., Flather, R., 1994a. Forecast and hindcast simulations of the Braer oil spill. Mar. Pollut. Bull. 28, 219-229.

Proctor, R., Flather, R.A., Elliott, A.J., 1994b. Modelling tides and surface drift in the Arabian Gulf: application to the Gulf oil spill. Cont. Shelf Res. 14, 531-545.

Proehl, J.A., Lynch, D.R., McGuillicuddy, D.J., Ledwell, J.R., 2005. Modeling turbulent dispersion on the North Flank of Georges Bank using Lagrangian particle methods. Cont. Shelf Res. 25, 875-900.

Pugh, D.T., 1987. Tides, Surges and Mean Sea Level. Wiley, Chichester, p. 472.

Sofianos, S.S., Johns, W.E., 2007. Observations of the summer Red Sea circulation. J. Geophys. Res. 112 (C06025), http://dx.doi.org/10.1029/2006JC003886.

Sotillo, M.G., Alvarez-Fanjul, E., Castanedo, S., Abascal, A.J., Menendez, J., Emelianov, M., Olivella, R., García-Ladona, E., Ruiz-Villareal, M., Conde, J., Gómez, M., Conde, P., Guierrez, A.D., Medina, R., 2008. Towards and operational system for oil-spill forecast over Spanish waters: initial developments and implementation test. Mar. Pollut. Bull. 56, 686-703. 